\title{
MATERNAL C-REACTIVE PROTEIN IN PREGNANCY AND ITS RELATION WITH EARLY ONSET NEONATAL SEPSIS
}

\author{
Muhammad Zahid, Saeed Zaman*, Sohail Shahzad*, Sajid Ali Shah*, Sana Javed*, Ammara Mushtaq Khan* \\ Combined Military Hospital Sargodha/National University of Medical Sciences (NUMS) Pakistan, *Combined Military Hospital Quetta/ \\ National University of Medical Sciences (NUMS) Pakistan
}

\begin{abstract}
Objective: To determine association of early-onset neonatal sepsis in newborns of serum C-reactive protein positive mothers. Study Design: Cross sectional analytical study.

Place and Duration of Study: Pediatrics department, Combined Military Hospital Quetta, from Sep 2016 to Mar 2018.

Methodology: A total of 105 neonates (both gender) of all mothers who were C-reactive protein positive were enrolled in this study using inclusion and exclusion criteria. Neonatal sepsis was diagnosed by clinical examination, which was carried out by senior pediatrician, blood complete picture and C-reactive protein. Neonates were treated as per departmental protocol.

Results: Out of total 105 patients, $46(44 \%)$ were male and 59 (56\%) were female neonates. Amongst the babies of 105 Creactive protein positive mothers, 79 babies were having signs and symptoms of neonatal sepsis and 26 babies were having no signs and symptoms of neonatal sepsis with statistically significant relation between maternal C-reactive protein and neonatal sepsis of $p$-value $<0.05$.

Conclusion: Increased maternal C-reactive protein level is associated with increased risk of neonatal sepsis. Maternal Creactive protein may be used as a good screening tool for early detection of neonatal sepsis.
\end{abstract}

Keywords: C-reactive protein, Low birth weight, neonatal mortality, Neonatal sepsis, Pre term babies.

\footnotetext{
This is an Open Access article distributed under the terms of the Creative Commons Attribution License (https://creativecommons.org/licenses/by-nc/4.0/), which permits unrestricted use, distribution, and reproduction in any medium, provided the original work is properly cited.
}

\section{INTRODUCTION}

Neonatal sepsis is defined as systemic infection which occurs in newborn less or equal to four weeks of age. Based on age of onset early neonatal sepsis has been defined as bacterial meningitis or bacteremia in term infant $<7$ days or $\leq 3$ days in newborn admitted in NICU. Early onset neonatal sepsis may also be caused by fungal or viral infection and need to be differentiated from bacterial infection ${ }^{1}$. According to UNICEF report each year about 3 million neonates die globally with a world-wide neonatal mortality rate of about 4/1000 live births ${ }^{2}$. About 1.4 million neonatal deaths are caused by neonatal sepsis. The burden of neonatal sepsis varies by geographical areas and neonatal and maternal risk factors. The use of intra partum antibiotics has reduced the incidence of neonatal sepsis ${ }^{3,4}$. Fetal factors contributing to EONS include low birth weight, prematurity, instrument assisted delivery and congenital anomalies 5 . Maternal factors contributing to EONS include premature rupture of membranes, meconium stained amniotic fluids, multiple digital vaginal examinations and spontaneous onset of labour ${ }^{6}$.

Diagnosis of congenital infection is desirable for prompt treatment and to prevent long term disability of newborns with neonatal sepsis. Different modalities

Correspondence: Dr Muhammad Zahid, Child Specialist, Department of Peadiatrics, CMH Sargodha Pakistan

Received: 22 Nov 2019; revised received: 18 Jan 2020; accepted: 22 Jan 2020 have been introduced for congenital infection diagnosis but most of them are invasive including amniocentesis for amniotic fluids cytokines and white blood cell counts ${ }^{7}$. Maternal IL-6 has been shown to be good predictor of EONS. IL-6 is considered to be the primary trigger of C-reactive protien (CRP) so maternal CRP can also be predictive of congenital infections and EONS8.

CRP and ESR both are used for assessment of inflammation. ESR is a non-specific measure of inflammation. CRP measurement is a direct determination of an APP and its serum levels increases rapidly during inflammation and its variation is wider than that of ESR. Unlike ESR, anemia, polycythemia, spherocytosis, macrocytosis, or hypergammaglo-bulinemia has no effect on level of CRP. Serial monitoring is done to monitor the evolution of infectious, autoimmune, and other diseases 9 . The rationale of our study was to find relation of positive CRP in mothers with early neonatal sepsis within 7 days after birth. It would greatly help not only in in early recognition of neonatal sepsis but also pro-mote antibiotic stewardship, preventing injudicious use of antibiotics in this early age. Moreover it will be of great value in recognizing burden of sepsis among neonates for prompt initiation of treatment.

\section{METHODOLOGY}

This study was carried out at Neonatal intensive care unit of Combined Military Hospital Quetta, from 
September 2016 to March 2018. Study was reviewed and approved by ethics and research committee (CMH QTA-IRB/009 dated 22 Oct 2019). Sample size was calculated using World Health Organization (WHO) calculator (1.1) with confidence level $=95 \%$, anticipated population proportion $=70 \%$, absolute precision required $=5 \%$ and sample size of 105 . Non-probability consecutive sampling was used. It was an analytical study. All term and preterm infants, whose mothers were having positive CRP results, included in the study. Sampling technique used was non probability consecutive sampling. Inclusion criteria used was neonates of serum CRP positive mothers of either gender with neonatal age $<72$ hours. Twin babies, congenital anomalies, metabolic disorders and with maternal history of eclampsia, hepatitis, cardiovascular disease and rheumatoid diseasewere excluded from the study. The parents of the patients were explained accordingly and informed written consent was taken after assuring them, benefits and risks of the study and risks. Neonatal sepsis was diagnosed on the basis of history, clinical examination, which was carried out by senior pediatrician. All the lab investigations were reported by the concerned experienced pathologist having minimum of 5 years' experience. Patients were looked for symptoms and signs of neonatal sepsis like lethargy, refusal to feed, off color, vomiting, hypothermia and fits. Complete blood count and CRP were sent to laboratory. Necessary information including name, age and gender was recorded as per designed proforma. All the patients with neonatal sepsis were admitted and standard treatment as per departmental protocol was given. The patients were discharged once stable.

Data was entered and analyzed using SPSS-22. For qualitative variables, frequency and percentage were calculated. For quantitative variables, mean and standard deviation were calculated. Chi-square was applied and a $p$-value $\leq 0.05$ was considered as significant.

Early-onset neonatal sepsis was defined as laboratory evidence of decreased platelet count $(<150,000 /$ $\mu \mathrm{L})$ and positive CRP at $\leq 72 \mathrm{hr}$ after birth with supporting clinical evidence of sepsis (lethargy, refusal to feed, off-color, febrile). CRP positive mothers were defined as mothers with serum CRP levels $>6 \mathrm{mg} / \mathrm{l}$.

\section{RESULTS}

Total number of patients in our study was 105 . Out of 105 patients $46(44 \%)$ neonates were boys and $59(56 \%)$ neonates were girls. The relation of gestational age with early onset neonatal sepsis was shown in
table-I. Mean birth weight of babies included in the study was $2.51 \pm 0.878 \mathrm{~kg}$. Babies with birth weight $<1.5 \mathrm{~kg}$ were 15 , between 1.5 and $2.5 \mathrm{~kg}$ were 33 , between 2.5 and $3.5 \mathrm{~kg}$ were 45 and $>3.5 \mathrm{~kg}$ were 12 . (tableII). The association of age in hours to early onset neonatal sepsis was shown in table 3.The correlation of quantitative maternal CRP with early onset neonatal sepsis was presented in table-IV.

Table-I: Gestational age (weeks) with respect to neonatal sepsis.

\begin{tabular}{l|c|c}
\hline \multirow{2}{*}{$\begin{array}{l}\text { Gestational } \\
\text { Age (weeks) }\end{array}$} & \multicolumn{2}{|c}{ Neonatal Sepsis } \\
\cline { 2 - 3 } & Yes & No \\
\hline$<32$ & $24(22.8 \%)$ & $2(1.9 \%)$ \\
\hline $32-37$ & $45(42.8 \%)$ & $3(2.8 \%)$ \\
\hline$>37$ & $10(9.5 \%)$ & $21(20 \%)$ \\
\hline
\end{tabular}

Table-II: Birth weight $(\mathrm{Kg})$ with respect to neonatal sepsis.

\begin{tabular}{l|c|c|c}
\hline \multirow{2}{*}{$\begin{array}{l}\text { Birth Weight } \\
\mathbf{K g})\end{array}$} & \multicolumn{2}{|c|}{ Neonatal Sepsis } & \multirow{2}{*}{$p$-value } \\
\cline { 2 - 3 }$<$ & Yes & No & \\
\hline$<1.5$ & $8(7.6 \%)$ & $7(6.6 \%)$ & \\
\hline $1.5-2.5$ & $28(26.6 \%)$ & $5(4.7 \%)$ & \multirow{2}{*}{0.013} \\
\hline $2.5-3.5$ & $37(35.2 \%)$ & $8(7.6 \%)$ & \\
\hline$>3.5$ & $6(5.7 \%)$ & $6(5.7 \%)$ & \\
\hline
\end{tabular}

Table-III: Association of age of baby in hours with neonatal sepsis.

\begin{tabular}{l|c|c|c}
\hline \multirow{2}{*}{$\begin{array}{l}\text { Age of Baby } \\
\text { (Hours) }\end{array}$} & \multicolumn{2}{|c|}{ Neonatal Sepsis } & \multirow{2}{*}{-value } \\
\cline { 1 - 3 }$<12$ & Yes & No & \\
\hline $12-24$ & $31(29.5 \%)$ & $12(11.4 \%)$ & \multirow{2}{*}{0.762} \\
\hline$>24$ & $40(38.1 \%)$ & $11(5.7 \%)$ & \\
\hline
\end{tabular}

Table-IV: Association maternal C-reactive protein and neonatal sepsis.

\begin{tabular}{l|c|c|c}
\hline \multirow{2}{*}{$\begin{array}{l}\text { Maternal C- } \\
\text { reactive protein }\end{array}$} & \multicolumn{2}{|c|}{ Neonatal Sepsis } & \multirow{2}{*}{ P-value } \\
\cline { 2 - 3 }$>6-24$ & Yes & No & \\
\hline $25-48$ & $35(33.3 \%)$ & $17(16.1 \%)$ & \multirow{2}{*}{0.011} \\
\hline$>48$ & $31(29.5 \%)$ & $2(1.9 \%)$ & \\
\hline
\end{tabular}

Out of 105 mothers who were CRP positive, 79 had babies (35 males and 44 female neonates) who were having signs and symptoms/lab evidence of neonatal sepsis and babies of rest of the mother's i.e. 26 were having no signs and symptoms/lab evidence of neonatal sepsis with statistically significant relation between maternal CRP and neonatal sepsis $p$-value $\leq 0.05$.

\section{DISCUSSION}

Different number of inflammatory markers are used for early detection of infection in children including CRP, interleukins, procalci-tonin and tumor necrosis factor etc. CRP is the most studied inflammatory marker and found to be the most valuable factor for detection of maternal infection during pregnancy. 
CRP is a very sensitive marker of infection. It rises much earlier than the constitutional signs and symptoms of infection. It is a rapid, simple and a safe test of maternal infection detection. Raised CRP to a significant level during pregnancy indicates maternal infection $^{10}$.

In this study, we also used CRP as an inflammatory marker for maternal infection as other inflammatory markers like interferons, interleukins were not available in our setup except procalcitonin which was not cost effective.

During pregnancy maternal infection is associated with increased morbidity and mortality. Moreover, intra uterine infection is a risk factor for preterm labor which not only further add to it but also affects good outcome badly. This is the reason that early detection and treatment of maternal infection during pregnancy is of great significance as this will help in decreasing neonatal mortality and morbidity ${ }^{11}$.

The main feature of our study was the increased rate of neonatal sepsis with positive maternal CRP. It was further observed that with increasing maternal CRP (quantitative) more neonates developed neonatal sepsis. Statistically, significant relation was found between positive maternal CRP and early neonatal sepsis with $p$-value $=0.011$. Few studies have been done to show relation of maternal CRP with neonatal infection. Leena et al, showed that elevated maternal serum amyloid $\mathrm{A}$, haptoglobin and CRP were related with positive amniotic fluid culture and neonatal sepsis ${ }^{12}$.

Mithal et al, showed that positive maternal CRP is not only a good predictor of maternal infection but also of early neonatal sepsis ${ }^{13}$. The same findings were seen in our study as well. However, study done by Mehmet et al, showed no relation of positive maternal CRP with neonatal infection which was contrary to our results ${ }^{14}$.

Hao et al, studied comparing of role of maternal CRP and procalcitonin (PCT) as marker of intrauterine infection with that of neonatal sepsis. They concluded that maternal PCT had little value as a marker intrauterine infection but both cord blood and maternal blood CRP level could be used as a predictor of neonatal infection ${ }^{15}$.

Ivana et al, showed that positive maternal CRP was linked with microbial invasion of amniotic cavity (MIAC) and intra amniotic infection (IAI) and these patients were having the high quantitative values of $\mathrm{CRP}^{16}$. A recent study has shown that maternal CRP is of great value for EONS prediction and a maternal
CRP $<8 \mathrm{ng} / 1$ has a good negative predictive value for EONS and over treatment of these neonates (invasive intervention and antibiotics) may be avoided. In one study including 48 CRP positive mothers, 36 (70\%) neonates had early onset neonatal sepsis ${ }^{17}$.

Another finding in our study was that the incidence of neonatal infection was significantly high in premature and low birth babies as compared to term and normal weight babies. Tshotetsi et al, also reported strong association between neonatal infection and preterm/low birth weight babies ${ }^{18}$.

To implement maternal CRP during pregnancy as a screening test for the detection of neonatal infection, it is necessary to carry out similar sort of studies in large and multiple centers. The shortcomings of our study are that it is a single centered study and the sample size was small and so the results drawn may not be implemented on general population.

\section{ACKNOWLEDGMENT}

We thank Combined Military Hospital Quetta for providing us all resources to carry out our study in the best possible manner.

\section{CONCLUSION}

Maternal CRP was found to be an easily available, safe and noninvasive test. Increased maternal CRP level is associated with increased risk of neonatal sepsis. Maternal CRP may be used as a good screening tool for early detection of neonatal sepsis. Early detection and prompt treatment of neonatal sepsis may lead to improved neonatal outcome and may result in decreased neonatal mortality and morbidity.

\section{CONFLICT OF INTEREST}

This study has no conflict of interest to be declared by any author.

\section{REFERENCES}

1. Fuchs A, Bielicki J, Mathur S, Sharland M, Van Den Anker JN. Reviewing the WHO guidelines for antibiotic use for sepsis in neonates and children. Paediatr Int Child Health 2018; 38(Suppl1): S3-15.

2. Blencowe $\mathrm{H}$, Cousens $\mathrm{S}$. Review: addressing the challenge of neonatal mortality. Trop Med Int Health 2013; 18(3): 303-12.

3. Shane AL, Stoll BJ. Neonatal sepsis: progress towards improved outcomes. J Infect 2014; 68(1): S24-S32.

4. Polin RA, Papile LA, Baley JE, Bhutani VK, Carlo WA, Cummings J, et al. Management of neonates with suspected or proven early-onset bacterial sepsis. Pediat 2012; 129(5): 1006-15.

5. Simonsen KA, Anderson-Berry AL, Delair SF, Davies HD. Earlyonset neonatal sepsis. Clin Microbiol Rev 2014; 27(1): 21-47.

6. Tita AT, Andrews WW. Diagnosis and management of clinical chorioamnionitis. Clin Perinatol 2010; 37(2): 339-54.

7. Wang X, Buhimschi CS, Temoin S, Bhandari V, Han YW, Buhimschi IA. Comparative microbial analysis of paired amniotic fluid 
and cord blood from pregnancies complicated by preterm birth and early-onset neonatal sepsis. PLoS One 2013; 8(2): e56131-35.

8. Prashant A, Vishwanath P, Kulkarni P, Narayana PS, Gowdara $\mathrm{V}$, Nataraj SM, et al. Comparative assessment of cytokines and other inflammatory markers for the early diagnosis of neonatal sepsis-a case control study. PloS One 2013; 8(7): e68426-30.

9. Ullah W, Thalambedu N, Haq S, Saeed R, Khanal S, Tariq S, et al. Predictability of CRP and D-Dimer levels for in-hospital outcomes and mortality of COVID-19. J Comm Hosp Int Med Perspect 2020; 10(5): 402-08.

10. Mhada TV, Fredrick F, Matee MI, Massawe A. Neonatal sepsis at Muhimbili National Hospital, Dar es Salaam, Tanzania; aetiology, antimicrobial sensitivity pattern and clinical outcome. BMC Public Health 2012; 12(1): 904-910.

11. Jeon JH, Namgung R, Park MS, Park KI, Lee C. Positive maternal C-reactive protein predicts neonatal sepsis. Yonsei Med J 2014; 55(1): 113-17.

12. Imdad A, Mullany LC, Baqui AH, El Arifeen S, Tielsch JM, Khatry SK, et al. The effect of umbilical cord cleansing with chlorhexidine on omphalitis and neonatal mortality in community settings in developing countries: a meta-analysis. BMC Public Health 2013; 13(3): 1-1.
13. Mithal LB, Palac HL, Yogev R, Ernst LM, Mestan KK. Cord blood acute phase reactants predict early onset neonatal sepsis in preterm infants. PloS One 2017; 12(1): e0168677-82.

14. Kutuk MS, Bastug O, Ozdemir A, Adnan Ozturk M, Tuncay Ozgun M, Basbug M, et al. Relationship between maternal creactive protein level and neonatal outcome in patients with preterm premature rupture of membranes treated with Ampicillin and Azithromycin. J Obstet Gynaecol 2016; 36(6): 772-77.

15. Hao W, Song J, Li G, Han B. Procalcitonin and CRP in neonatal infection, a comparison study between intrauterine infection and non-intrauterine infection. Biomed Res 2017; 28(14): 6256-59.

16. Musilova I, Kacerovsky M, Stepan M, Bestvina T, Pliskova L, Betal Z. Maternal serum C-reactive protein concentration and intraamniotic inflammation in women with preterm prelabor rupture saof membranes. PloS One 2017; 12(8): e0182731-35.

17. West BA, Peterside O, Ugwu RO, Eneh AU. Prospective evaluation of the usefulness of C-reactive protein in the diagnosis of neonatal sepsis in a sub-Saharan African region. Antimicrob Resist Infect Control 2012; 1(1): 1-5.

18. Tshotetsi L, Dzikiti L, Hajison P, Feresu S. Maternal factors contributing to low birth weight deliveries in Tshwane District, South Africa. PloS One 2019; 14(3): e0213058-62. 